borders of the USSR is perhaps the major reason that the Soviets are not members of the international high-technology club" (p. 515). The author coins a new word to comprehend a system in which a great variety of official permits parallel the expression of options in prices-the "documonetary" economy. In the assessment of the application of the Final Act of Helsinki by the USSR, the West was much exercised by calibration (for example, how to set the liberalization of personal movement and of the media against confidence-building measures of a military or strategic nature). Berliner's book shows that the Kremlin might be wise to call for its own domestic cost-benefit analysis at a time when the growth of national income has sunk to 3.5 percent.

MICHAEL KASER

St. Antony's College, Oxford

\title{
ECONOMIC SYSTEMS: ANALYSIS AND COMPARISON. By Vaclav Holesov- sky. New York: McGraw-Hill, 1977. xiv, 495 pp. \$15.95.
}

Comparative economic systems is an untidy field. Its scope is imprecise and its theory is rudimentary compared to the rigor achieved in other areas of economics. Despite these serious limitations, several excellent texts are available which effectively articulate the state of the art at the same time that they try to establish how comparative economic sysems should best be analyzed. Vaclav Holesovsky's Economic Systems is a welcome addition to this growing stock of systems texts. The book is organized thematically in two broad divisions, the first (chapters 1-6) deals with the issue of systems classification, the second (chapters 7-18) focuses on how various systems cope with problems of factor allocation, production, product distribution, full employment, income distribution, inflation, growth, enterprise management, agriculture, and foreign trade.

Unlike some texts which emphasize "pure theory," or others which stress country studies, Professor Holesovsky has written a unitary work that contrasts how diverse market and planned economies attempt to resolve similar micro- and macroeconomic disequilibria. The virtue of this approach is that it provides a coherent framework for comparison, and at the same time demonstrates how alternative strategies of socioeconomic engineering express a "human determination to tame, subdue, regulate, stimulate, modify and reform . . the social forms of economic activities," which the author perceives as a primal quest for social freedom (p. 480). Overall the book is very well written and is enlivened by Holesovsky's personal commitment to his subject matter.

Some difficulties must be noted, however. Unless students already possess considerable knowledge of general economic theory and the institutional evolution of the national economic systems discussed, they may well find the thematic approach too abstruse. Also, it would have been preferable if the way various systems operated had been analyzed as "theories of operation" requiring empirical verification, rather than as being descriptively self-evident. Perhaps the great effort put into resolving the classification problem has obscured the fact that, as a matter of scientific knowledge, we do not know with great certainty how any system really functions behind the reassuring façade of consistent macrodescriptive abstraction. Finally, the book fails to provide an adequate understanding of the global dynamics of each system, that is, how various disturbances affect all aspects of a system simultaneously. This is, of course, a very difficult matter, but it is nonetheless vital for discriminating preferred and nonpreferred theories of systems behavior, as well as for evaluating comparative systems merit. 